\title{
CRAFT EDUCATION IN DESIGN
}

\author{
Monikuntala DAS ${ }^{1}$ and Amarendra Kumar DAS ${ }^{2}$ \\ ${ }^{1}$ Research Scholar, Department of Design, IIT Guwahati, India \\ ${ }^{2} \mathrm{PhD}$, Professor, Department of Design, IIT Guwahati, India
}

\begin{abstract}
What we call crafts today has historically been utilitarian products for local consumption. Craft, through its generative learning and systematic distribution of work entails a volume of nonvocalised ethics within a craftsman guild. These very utilitarian products have currently become pieces of curio in today's living room walls and exhibition spaces. Epistemology of crafts has explicit associations to the daily livelihoods, socio-economic backgrounds, utilitarian aspects, history and anthropology of local sustenance. From the perspective of design, there is a story of creative utilitarianism which provides a deep understanding of an ethical and philosophical theory stating that 'the best action is the one that maximises utility and produces the greatest well-being of people though one's creativity'. [1]

Post industrialisation, design sees a call out to go back to one's roots to obscure local identities and revive the cultural diversities destroyed by the industrialist mindset. In the post-modern world, creative utilitarianism allows designers to be creative for themselves rather than the industry. This eventually proliferates exposure of modern design to fresh ideation. This understanding is highly required today for young upcoming designers to venture beyond form and figure explorations and infuse content into design. Integration of wholesome craft knowledge into design education will open a portal for fresh post-modern content. It shall teach the students mass customisation alongside a knowledge to work with Indigenous communities and identities. Thus, this paper tries to justify the importance of craft education in design by throwing light on the various aspects associated with the design education sector of the upcoming generation of young designers.
\end{abstract}

\section{Keywords: Creative utilitarianism, postmodern design, craft education}

\section{INTRODUCTION}

The craft sector provides livelihood and employment to 20 million people of India [2], which constitutes $15 \%$ of the country's population. Craft communities of India survive on a lifestyle-based framework which includes handing down knowledge from one generation to the next. There is a synergy of execution and hierarchy of labour and more so, a deeper philosophy of "work being sustenance' within the community. It is an incredible identity of the Indian solitude and provides a platform for the creativity of Indian designers to develop their indigenous identity.

\section{ANALYSING CRAFT INGREDIENTS}

Craft when viewed though a holistic lens is a mode of knowledge, education, design and livelihood integrated with sustainability through environment friendly products. Factors associated with crafts which make it a purposeful integrated enterprise can be explained through the following determinants.

- Society: Craft is a family execution which has a close connection to India's caste system. Specific lower caste communities of the society involve themselves in making crafts. The prevailing higher castes consider it to be a non-elite chore. But simultaneously, due to the quality of the product, these very items of craft become the community curio in which the elites take pride in as items of respect, adorned and distributed in prestigious or ceremonial occasions.

- Education: Craft education in communities is transferred through generations informally. The generation next visually learns from their family members in household courtyards and eventually takes part as they grow older. The low caste community stays in remote locations and has minimal access to formal education, thus depending on vernacular education for survival. 
- Skill based learning: Craft is exceptionally a skill-based learning which focuses on the development of muscle memory for hand execution. This is developed through apprenticeship via many hours of practice over cumulated years. The decentralised system allows the breakdown of the manufacturing process, for craftsmen to find and pursue their individual expertise.

- Market: The market which their products cater to, are of various kinds. The products fall under the category of Traditional, Modern, Curative and Functional. The craftsmen keep working on their products out of expertise, irrespective of category. They are taken forward either by middlemen or entrepreneurs for their respective markets.

- Technology: As time has passed and crafts have evolved, newer techniques for easier disposal have been on demand, so that the numbers of produce come at par in competition with the everexpanding industrial market. Also, the same condition applies for the quality of products. This has called for new material processes and technological inputs.

- Product Design: The validity of crafts in today's modern scenario challenges the delivery of utilitarian products which conform to urban lifestyle. This requires the need for diversification of products by understanding the design along the perspectives of form, function and society. This happens to be a fundamental aspect for the survival of crafts in the modern world.

- Aesthetics: Apart from utilitarian design expected by the middle-class urban crowd, there is a lot of scope for crafts amongst modern elite buyers. They have the time, money and exposure to understand exquisiteness in Contemporary, Retro, Ethnic and Preservative Designs. To deliver such aesthetics to satiate the elite crowd, one requires an elaborate study of evolution and must be able to identify and differentiate their elements for ultimate execution.

- Knowledge: The knowledge regarding crafts, its epistemology, techniques, work ethics etc stays amongst the communities as a non-vocalised comprehension. Majority of this knowledge has not been documented and remains oblivious to the corresponding design communities. Apart from recognition, the documentation and propagation of this knowledge shall provide a base for future expeditions. If not, entrepreneurs venturing into this domain would have to start from the very basics, which would be an extensive research in itself.

\section{DECADENCE OF CRAFT}

When industrialisation took over the modes of production in the mid-20th century in India, handmade products fell out of preference and were extremely neglected till late 20th century [3]. Crafts went from the forefront of a rising economy to a point where it required preservation. There are many reasons which led to this drastic devastation of crafts. A few of them are mentioned below:

- Crafts remained exclusively within the crafts community. The integrity of the teaching methods prohibited its understanding from any other group of the society. There was no appropriate propagation of their techniques and teachings outside their own community due to craftsmen humbleness. This distanced people from empathising with their crisis, post industrialisation.

- Industrialisation produced products made out of materials which could stand longer than the durability of materials used in crafts. This led to the replication of craft products in materials of mass production. This eventually led to the shifting of production houses from the original vernacular craft locations to industrial centres where the craft experienced loss of local embossing patterns and original utilitarian designs. The industrially replicated craft products were more favoured by the modern public and gradually reduced the sale of the original craft produce.

- Craft started to be seen in a manner in which its existence seemed delusional to the ever-growing industrial products. The people who adorned craft wished beauty out of it rather than utilitarian use. So, the craftsmen shifted their focus to making 'pretty' products, rather than utilitarian, which could at least be a curio, all in order to guarantee their income and their livelihoods.

- In order to enhance the demand for craft products, there was a dire need to understand design though perspectives of form, function and society. Since the craftsmen of India have very less exposure to existing design and the needs and demands of the urban society, they were not able to create fresh ideas which could be integrated with their skills to improve their sale.

- With the loss of economic edge and income potential, the newer generation of craftsmen remained sceptical about accepting the profession as a lifelong commitment and thus learned the craft insignificantly. With the loss of techniques after passing of generations, the advocating in offspring was also weak. 
- Simultaneously, Modern design with its emphasis on industrial production prevailed. A new aesthetics based on industrial processes emerged forming the base of modern industrial design. Quest for new forms based on machine production led to the discovery of machine aesthetics nurtured by movements in modern art with traits of functionality and simplicity. Craft was excluded from the aesthetic domain though it preserved its decorative character.

- Eventually, post modernism saw a call out to go back to one's roots to obscure local identities and revive the cultural diversities destroyed by the modern industrialist mindset. Disillusion with the concepts of 'Progress and better life' promised by modern industry lead to a new thinking. Designers were frustrated by the limited product expressions controlled by economy of production and distribution as well as concerns of marketing for mass consumption. A new need for post-modern design to discover and assert meaningful design is on the anvil [4].

\section{CRAFT EDUCATION IN DESIGN: INDIAN STATUS}

As everywhere else in the world, the loss of craft through industrialisation was very highly evident to the post-modern designers of India and thus, with the teachings of the Bauhaus and Ulm Schools of Design being 'Art into Industry' [5] and 'Designer's Societal Responsibility' [6] respectively, India introduced the following chronologically to facilitate this knowledge amongst young designers.

- National Institute of Design (NID), Gujarat: India's first institute of Design in 1961 was NID in Gujarat. The Institute's intention was to become a repository of both traditional and modern design knowledge, experience and information. The institute encouraged the design of products and systems of everyday use, along affordability for the masses. Through 'thinking global and acting local' teaching, it anchored itself to the cultural strengths of India. Currently, within the Curriculum, NID provides courses in Ceramic, Glass and Textile Design within the Craft Domain at bachelors and masters level. It incorporates craft towards future scope of mass production and newer technologies [7]. Although the students are being given extensive exposure to craftsmen and their work, they receive very less experience on the real-life market front, about the challenges of saleability and customer acceptability of craftsman produce over industrial produce.

- Industrial Design Centre (IDC) at IIT Bombay: In 1969, IDC, with a similar aim as NID, directed itself to actualise the design concepts with a broad technological support from IIT as a whole. IDC actuated to improve the quality of life of the country's disadvantaged population by looking into grass root level problems of socio-economic and cultural diversities. Within this curriculum, the bachelors programme includes an advent into Design, Society, Culture and Environment and an introduction to Design and its relationship to Art, Craft and Technology through the course of Design and Human Evolution. The master's programme holds Craft Creativity and Post Modernism elective and incorporates understanding Nature of Materials and Processes as Industrial Design course content [8]. Though the curriculum introduces crafts, it has no core course which dispenses the knowledge about the challenge stories of a craft community.

- School of Planning and Architecture (SPA), Delhi and IIT Delhi: In 1992, SPA Delhi and IIT Delhi inaugurated their Masters courses in Design along similar guidelines from NID and IDC. SPA provides craft introduction through Design History and Theory course, Applied Arts and Crafts elective and a suggested elective in Craft Documentation [9]. The students indulge into craft sector depends highly upon the availability of an interested faculty. Whereas IIT Delhi provides no course or elective in craft knowledge whatsoever as it comes from a more technological background [10].

- Department of Design (DoD) at IIT Guwahati: IIT Guwahati started Bachelors and Masters course in Design in 1995, to enkindle technical minds with a passion for innovation in technology driven by an appreciation of design. Although the region of North East India where Guwahati is located is filled with a variety of local crafts, due to its technological background, there is no core course in the curriculum based on crafts [11]. The option of using craft materials by the students lie on the interest and availability of faculty members, captivated to pursue the domain.

- Indian Institute of Crafts and Design (IICD), Jaipur and Craft Development Institute (CDI), Srinagar: The IICD Jaipur in 1995 and CDI Srinagar in 2005 developed a learning model which sought to develop design programmes focused on future techniques of handicrafts and craft uniqueness. The institutes developed partnerships with various craft sector stakeholders like Master Artisans, Craft Clusters, Craft NGOs, Government Agencies, Experts and Industry 
players and leveraged this network to the students. IICD provides Bachelors and Masters courses in Fired Material Design, Soft Material Design, Hard Material Design, and Fashion Design [12], whereas CDI offers two flagship professional education programmes: Masters in Craft Management \& Entrepreneurship and Textile Design \& Application [13]. The model preserves the technique of the craft, but innovative product design incorporation needs to take a further step.

- University Grants Commission (UGC), Delhi: Meanwhile, UGC of India provides guidelines for skill-based education under National Skill Qualification Framework. It provides Diploma, Undergraduate, Postgraduate and Research Level courses to create 'industry fit' skilled workforce leading to gainful employment and entrepreneurship, crucial for India's socioeconomic development [14].

The above analysis states that two dominant education models exist side by side - the technological model of the IIT's and craft uniqueness model of the craft institutes. They have not effectively merged due to which Indian Post-Modern Design is at a loss. Design education needs a definitive merge of Craft, Design and Technology to revive from the post industrialisation design crisis.

\section{CRAFT DESIGN IN MARKET: CURRENT STATUS}

In the sector of Post-Modern entrepreneurship, a few brand identities have been able to successfully develop themselves with a foothold in the craft sector. These brands have incorporated designers and local craftsmen to give their produce an edge over the available, making them acceptable and sought for in the urban market. Three examples of such success ventures have been discussed below.

- Fabindia: It was founded in New Delhi in 1960 by John Bissell with the strong belief that there was a need for marketing the vast and diverse craft traditions of India and thereby help fulfil the need to provide and sustain employment. They blended indigenous craft techniques with contemporary designs to bring aesthetic and affordable products to today's consumers. They worked closely with artisans and designers by providing various inputs to maximise the handmade element in products of hand-woven textiles, hand block printing, hand embroidery or handcrafting home products. Currently their products range from garments, accessories, home furnishings, organic foods, personal care to handcrafted jewellery [15].

- Good Earth: In 1996, entrepreneur Anita Lal started her first store of Good Earth in Mumbai with the creative vision of integration tradition into design. She has incorporated various materials and artisans from the plethora of Indian crafts and has delivered a range of products satisfying the Indian elite pride, in a way neither kitsch nor ethnic. Good Earth has become a platform for craftspeople to connect with global craft enthusiasts. Anita Lal believes strongly that at an economic, social, and cultural level, we would be impoverished if we were to devalue our Indian crafts, which are the wellspring of our creativity [16].

- Studio Rhizome: Rebecca Reubens, an alumnus of NID Ahmedabad, through her work with bamboo furniture pieces, is working on the aspect of sustainability of daily livelihoods. Since it is both a local and global problem, she believes that we look into the bigger picture and simultaneously at the finer details [17]. She works extensively in ideating modern design into bamboo furniture, by working with local craftsmen and adding rope weaving patterns to deliver a delightful look to the furniture pieces.

There are many more upcoming initiatives which have oriented themselves toward the craft sector of the country and have opened up fresh opportunities for young designers to be part of. These enterprises provide a fitting example of successful entrepreneurship in the crafts domain through mindful work with a purpose. But since working in a craft sector requires an experience of some sort to be interested and productive, it would be helpful for the young designers to be exposed to craft culture at an early stage in their design education. This could also provide a lot of scope for their future imaginative enterprises.

\section{PROPOSAL: CRAFT SEMESTER IN BDES PROgRAMME}

Since craft culture is the upcoming assurance of the Post-Modern Design era, there is a strong need of its association with the design programmes of the country as it is blessed with innumerable crafts and its communities. As discussed earlier, the design education fraternity depends heavily on the individual interest and availability of a few faculty members within the country. This indigenous 
prospect with exploitable promises must not lie at the whim and fancy of such logistical issues. Thus, in retrospect, it has become an impending concern to teach the upcoming designers wholesomely about crafts and how to incorporate it into modern design.

Thus, the proposal is to introduce the students of bachelor's programme of design to a semester of Craft Education as a project semester in which they shall have to interact with any craft community of their choice, ideate and manufacture a batch of a product with the help of the craftsmen, and finally deliver the same to the immediate market for sale.

\section{HOW WILL THIS SEMESTER HELP}

The craft semester project can help the students in many different directions. The contributions to knowledge have been discussed below.

One of the most important learning from such a project would be manufacturing. It will teach them coordination for production and the multidisciplinary aspects of product development from material procurement to market delivery. It would include technology integration, execution through craftsmen, understand market demands and mass production timelines. The batch outcome would teach Designers mass customisation which would include moulding, jigs, fixtures and other craft related processes in their own innovative ideation. It will release them from the notion that craft production is frugal.

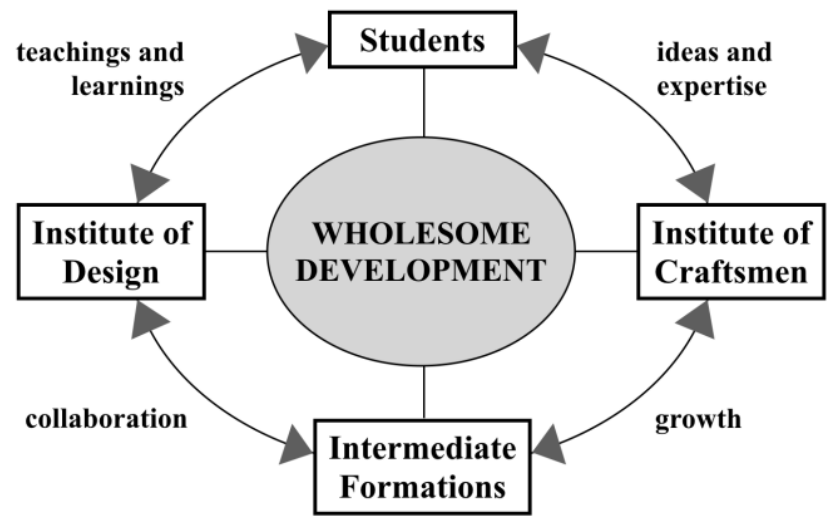

Figure 1. Advantages of Proposal

In the meantime, Designers will understand the socio-economic status, livelihoods and dynamics of the indigenous craft communities, make them humble enough to interact, and learn with experience how to deliver ideas and satisfy their expectations. It will be a platform in which one would be curious about 'How designers and craftsmen could learn from each other'. The students would understand their role as an industrial designer better in a real-life platform.

With the skill and execution of craft at access, designers will face the challenge of ideation on new use through craft possibilities. This shall help them grow as design thinkers, and eventually enhance their solidarity towards incorporation of modern design in craft. Before the venture into the field of Design, students are very less aware of the dynamics and details of culture and tradition. The introduction and understanding of the indigenous patterns, traditional symbols and motifs would inculcate values of identity and thus bring more depth into the designer's work through associations of the same, rather than considering mere form and figure explorations.

Since they would have already ventured into a real-life small-scale entrepreneurship, designers would be more confident post-graduation to take up initiatives for startups for their creative enterprises. A new genre of career opportunities, both government and private, shall also be on the rise for them through design since the country has realised its potential and is already generating economy through it.

Such a course would also manifest the interaction between the institute of Design and the institute of craftsmanship. Intermediate formations such as Non-Governmental Organisations (NGO's) helping the craftsmen would also experience growth from the collaboration. There would be a wholesome development amongst all the stakeholders.

On the whole, such a venture would lead to a world vision of future designers in the upcoming century, who would keep an eye on safeguarding the facets of indigenous design in the post-modern era and the untold future thereafter. 


\section{CONCLUSIONS}

Since craft is a handmade product, mass manufacturing to deliver numbers needs intended collaboration for production and marketing. Everybody in the craft community understands one's role. This understanding is utmost amongst the one who ideates and the one who creates. Also, with a very minimum delivery of verbal language, the effort of the event is understood. There is a work of dedication performed without imposing individuality. The income generated is also for the greater good of the community and there is a humble justified sharing. This is the beauty of habiting under the same cultural genesis.

To be a designer in the home ground, one needs to understand where our origins are. And sharing a similar historical background helps the designer to better comprehend the dynamics of the indigenous crowd, when an effort is put in. The problem arises when designers are not taught to appreciate this area of creative ability which could provide a platform for their individual creativities. Every designer must involve themselves in at least one craft related design and its execution so as to understand this very dynamic. They must relieve themselves from the stigma of local design and from the western influence and look into what is probably being ignored. The crux of the nation lies in the crafts and that is where the country's beauty is.

When such collaborative efforts are made between different institutions, the numbers provide a chance to gain an identity and prove its effectiveness, which could eventually gather matter for influence and thus upgrade and uplift the silent dedicated craftsmen.

\section{REFERENCES}

[1] Bentham J. An Introduction to the Principals of Morals and Legislation, 2009 (Dover Publications, Mineola).

[2] Viswanath B. Enumeration of Crafts Persons in India. Madras School of Economics, 2013, 19-42.

[3] Bhat J.A. and Yadav P. The Sector of Handicrafts and its Share in Indian Economy. Arabian Journal of Business and Management Review, S3, 2016.

[4] Rao A.G. Craft as a Post-Modern Venture: Experience in Bamboo Craft. In PD2008 $8^{\text {th }}$ Brazilian International Conference, Sao Paolo, October 2008.

[5] Droste M. Bauhaus 1919-1933, 1990 (Bauhaus-Archive Museum fur Gestaltung, Berlin).

[6] Krippendorff K. Designing in Ulm and Off Ulm. University of Pennsylvania Scholarly Commons, 2008.

[7] National Institute of Design. Available: http://www.nid.edu/institute/mandatemission-visionvalues.html [Accessed on 2019, 19 February].

[8] IDC School of Design IIT Bombay. Available: http://www.idc.iitb.ac.in/about/Vision_Mission.html [Accessed on 2019, 19 February].

[9] School of Planning and Architecture Department of Industrial Design. Available: http://spa.ac.in/User_Panel/UserView.aspx?TypeID=1248 [Accessed on 2019, 19 February].

[10] Department of Design Indian Institute of Technology Delhi. Available: http://design.iitd.ac.in/programmes-m-des.html [Accessed on 2019, 3 March].

[11] Department of DoD. Available: http://www.iitg.ac.in/design/Courses.html [Accessed on 2019, 19 February].

[12] Indian Institute of Crafts and Design, Jaipur UG Degree Programme. Available: http://www.iicd.ac.in/under-graduate-design/ [Accessed on 2019, 3 February].

[13] Craft Development Institute Srinagar, Education. Available: http://cdisgr.org/what_we_do_edu.html [Accessed on 2019, 18 February].

[14] University Grants Commission. Guidelines for providing Skill Based Education under National Skill Qualification Framework. UGC Guidelines, 2018, 3-7.

[15] 50 years of Fabindia. Available: http://www.fabindia.com/50-years-of-fabindia [Accessed on 2019, 5 March].

[16] Nair B. Good Earth, Anita Lal-founded family-owned luxury home décor company, credits focus on Indianness for its success. Available: http://economictimes.indiatimes.com/industry/services/retail/good-earth-anita-lal-foundedfamily-owned-luxury-home-decor-company-credits-focus-on-indianness-for-itssuccess/articleshow/60229057.cms [Accessed on 2019, 5 March].

[17] Reubens R. Bamboo from Green Design to Sustainable Design, 2012 (Rainbow Publishers, Ahmedabad). 